OPEN ACCESS

Edited by:

Claudio Fabricio Gonzalez, University of Florida, United States

Reviewed by: Jie Yin,

Institute of Subtropical Agriculture

(CAS), China

Elvira Maria Hebert,

Consejo Nacional de Investigaciones

Cientificas y Técnicas (CONICET),

Argentina

*Correspondence:

Yuan Zhao

zhaoyuan4CL52@126.com

Specialty section:

This article was submitted to Microbial Physiology and Metabolism, a section of the journal

Frontiers in Microbiology

Received: 11 July 2018 Accepted: 29 October 2018

Published: 20 November 2018

Citation:

Chang M, Zhao Y, Qin G and

Zhang $X(2018$

Fructo-Oligosaccharide Alleviates

Soybean-Induced Anaphylaxis

in Piglets by Modulating Gut

Microbes. Front. Microbiol. 9:2769.

doi: 10.3389/fmicb.2018.02769

\section{Fructo-Oligosaccharide Alleviates Soybean-Induced Anaphylaxis in Piglets by Modulating Gut Microbes}

\author{
Meinan Chang ${ }^{1}$, Yuan Zhao ${ }^{1 *}$, Guixin Qin ${ }^{1}$ and Xiaodong Zhang ${ }^{2}$ \\ ${ }^{1}$ Key Laboratory of Animal Production, Product Quality and Security, Ministry of Education, Jilin Provincial Key Laboratory \\ of Animal Nutrition and Feed Science, College of Animal Science and Technology, Jilin Agricultural University, Changchun, \\ China, ${ }^{2}$ Institute of Zoonosis, Department of Public Health, Jilin University, Changchun, China
}

Soybean-induced anaphylaxis poses a severe threat to the health of humans and animals. Some commensal bacteria, such as Lactobacillus and Bifidobacteria, can prevent and treat allergic diseases. Prebiotic oligosaccharides, a food/diet additive, can enhance health and performance via modulating gut microbes and immune responses. The purpose of this study was to examine whether fructo-oligosaccharides (FOS) could alleviate soybean-induced anaphylaxis by modulating gut microbes. Piglets ( 21 days of age) were sensitized with a diet containing $5 \%$ soybean and $30 \%$ peeled soybean meal. The treatment with $0.6 \%$ FOS started 1 day prior to sensitization and continued everyday thereafter. Blood was collected for measurements of immune indices. The DNA samples isolated from fresh intestinal contents of the middle jejunum (M-jejunum), posterior jejunum (P-jejunum), ileum, and cecum were used for gene sequencing based on 16S rRNA. Our results showed that there was an increase of glycinin-specific lgG, $\beta$-conglycinin-specific lgG, total serum lgG and lgE, and occurrence of diarrhea in piglets sensitized with soybean antigen. There was a decrease in interleukin 4 (IL-4) and IL-10 and an increase of interferon- $\gamma$ (IFN- $\gamma$ ) in piglets with FOS treatment, compared with the piglets without FOS treatment. Improvement of intestinal microbes was indicated mostly by the increase of Lactobacillus and Bifidobacteria in M-jejunum and the decrease of Proteobacteria in P-jejunum and ileum. The correlation analysis indicated that FOS treatment decreased those closely related to the key species of gut microbes. These results suggest that FOS can alleviate soybean antigen-induced anaphylaxis, which is associated with increased Lactobacillus and Bifidobacteria in M-jejunum and declined Proteobacteria in P-jejunum and ileum of piglets.

Keywords: soybean antigen, fructooligosaccharides, gut microbes, immune response, piglets

\section{INTRODUCTION}

Soybean is a species of legume and an ideal source of protein for humans and animals (Guo et al., 2007; Sun et al., 2008). However, many antinutritional factors are contained in soybeans, such as glycinin, $\beta$-conglycinin, agglutinin, which severely undermine its nutritional values (Huang et al., 2010; Zhao et al., 2011). Soybean-induced anaphylaxis in humans and young animals is attributed mainly to allergens such as glycinin and $\beta$-conglycinin (Van de Lagemaat et al., 2007). Patients with anaphylaxis often exhibit symptoms such as tremor, throat edema, rash, and acute asthma. Piglets 
with soybean-induced anaphylaxis can have symptoms such as diarrhea, dysbiosis of intestinal digestive system, and even death (Wang et al., 2014).

Previous studies have shown that traditional processing techniques such as heat treatment, high-pressure puffing, and fermentation (Tang and Ma, 2009; Zheng et al., 2017) can passivate allergens in soybeans. Recent studies demonstrated that the addition of exogenous active substances such as lipoic acid (Cho et al., 2004), plant extracts (Hao et al., 2010; Julie et al., 2010), probiotics (Ly et al., 2011), or prebiotics (Gourbeyre et al., 2013) can prevent and treat allergies effectively.

Commensal bacteria in the intestinal tract, such as Lactobacillus and Bifidobacteria, play a major role in maturation and homeostasis of the gut-associated immune system (Holt and Jones, 2000; Lanning et al., 2000). These microbes prevent and treat post-antibiotic diarrhea (Cruchet et al., 2003), allergic diseases (Shida et al., 2002; Fiocchi et al., 2012), and recurrence of inflammatory bowel disease (De Cruz et al., 2012).

Prebiotics are indigestible compounds that confer beneficial physiological effects on the host by modulating the composition and activity of microorganisms in the gut (Valcheva and Dieleman, 2016). Fructo-oligosaccharides (FOSs) are nondigestible oligosaccharides that are found naturally in a variety of fruits and vegetables such as artichokes, leeks, asparagus, potatoes, wheat, onions, bananas, and can stimulate the growth of Bifidobacteria and Lactobacillus in the colon of healthy individuals. It is reported that FOS can strengthen the immune function by regulating immunoglobulin, immune cells and their secreted inflammatory factors, as well as intestinal microbes (Delgado et al., 2012). Human studies indicate that galactooligosaccharides (GOS)/FOS can reduce significantly the plasma level of total IgE and IgG1, IgG2, and IgG3 in infants at risk for allergy (Van et al., 2010). In addition, Watanabe et al. (2008) showed that FOS can reduce 2, 4-dinitrofluorobenzene-induced contact hypersensitivity in mice by promoting proliferation of Bifidobacteria. Therefore, we hypothesized that dietary FOS can alleviate soybean antigen-induced anaphylaxis by modulating gut microbes. As pigs have similar genetic background and physiological characteristics as humans, they are used widely in research to study human health and diseases (Alizadeh et al., 2016). In this study, we evaluated the impact of FOS on anaphylaxis induced by soybean antigen protein in piglets by determining the expression of a series of inflammatory and immune factors (IgG, IgE, IFN- $\gamma$, IL-4, IL-6, IL-10, and TNF- $\alpha$ ) and the gut microbes. We aimed to find an effective strategy to inhibit the sensitization of antigen protein and explore the regulatory mechanisms of "host-microbiome" interaction.

\section{MATERIALS AND METHODS}

\section{Animals}

All piglets used in this experiment were approved by the Jilin Agricultural University Animal Care and Use Committee. Fifteen crossed (Yorkshine-Landrance-Duroc) barrows were weaned at 21 days of age and had an average weight of $6.81 \pm 0.58 \mathrm{~kg}$. The piglets were divided randomly into three groups of five each and housed in a livestock farmhouse located in Jilin Agricultural University, Changchun.

\section{Experimental Diets}

The ingredients and nutrients of the diet are shown in Table 1. The diet was formulated to meet NRC (2012) requirements. Piglets were assigned to three groups: the control group, the allergy group (5\% soybean and $30 \%$ peeled soybean meal), and the FOS group [ $5 \%$ soybean and $30 \%$ peeled soybean meal plus $0.6 \%$ FOS (Solarbio, Beijing, purity > 95\%)]. The soybean was purchased from Jilin Agricultural University soybean experimental field. The control diet, devoid of soybean protein, contained bran $(4.5 \%)$, whey powder $(7.19 \%)$, casein $(11.13 \%)$, fish meal $(2.00 \%)$, and digester tankage $(1.02 \%)$ as protein

TABLE 1 | Ingredient composition and nutrient levels of the diets.

\begin{tabular}{|c|c|c|}
\hline \multirow[t]{2}{*}{ Ingredient composition (\%) } & \multicolumn{2}{|c|}{ Dietary treatment } \\
\hline & Control diet & Allergy diet \\
\hline Peeled soybean meal & & 30.00 \\
\hline Soybean & & 5.00 \\
\hline Casein & 11.13 & \\
\hline Zeolite & 0.80 & 0.80 \\
\hline Corn & 65.70 & 52.10 \\
\hline Bran & 4.50 & 1.30 \\
\hline Limestone & 1.42 & 1.89 \\
\hline Whey powder & 7.19 & 0.00 \\
\hline Fish meal & 2.00 & 0.00 \\
\hline Digested tankage & 1.02 & 0.00 \\
\hline Salt & 0.65 & 1.00 \\
\hline Sucrose & 2.55 & 1.20 \\
\hline Vitamin mineral premix* & 0.85 & 1.00 \\
\hline Oil & 1.10 & 2.95 \\
\hline Phosphate & 0.58 & 2.00 \\
\hline Lysine & 0.29 & 0.45 \\
\hline Threonine & 0.12 & 0.19 \\
\hline Methionine & 0.10 & 0.12 \\
\hline Total & 100 & 100 \\
\hline \multicolumn{3}{|l|}{ Chemical analysis } \\
\hline Net energy (kJ/kg) & 10.24 & 10.24 \\
\hline Crude protein (\%) & 17.5 & 17.5 \\
\hline Lysine (\%) & 1.44 & 1.35 \\
\hline Methionine (\%) & 0.41 & 0.44 \\
\hline Threonine (\%) & 0.83 & 0.79 \\
\hline Arginine (\%) & 1.25 & 0.71 \\
\hline Leucine (\%) & 1.47 & 1.66 \\
\hline Isoleucine (\%) & 0.73 & 0.73 \\
\hline Calcium (\%) & 1.00 & 0.86 \\
\hline Phosphorus (\%) & 0.40 & 0.40 \\
\hline Natrium (\%) & 0.41 & 0.36 \\
\hline Chlorine (\%) & 0.62 & 0.53 \\
\hline
\end{tabular}

*Premix provided per kilogram of complete diet: vitamin A, 45,000,000 U; vitamin D3, 9,000,000 IU; vitamin E, 80,000 IU; vitamin K3, 5000 mg; vitamin B1, 8000 mg; vitamin B2, 20,000 mg; vitamin B6, 9000 mg; vitamin B12, 100 mg; nicotinamide, 100,000 mg; D-calpanate, 50000 mg; folic acid, 4000 mg; D-biotin, 500 mg; Cu, 320 mg; Fe, 175 mg; Zn, 125 mg; Mn, 55 mg; Se, 7.5 mg; and l, 20 mg. 
TABLE 2 | Effects of FOS on performance ${ }^{a}$, diarrheab, total serum IgG and IgE levels, glycinin, and $\beta$-conglycinin-specific lgG antibody OD units and cytokine concentrations in serum in soybean allergy protein-sensitized and control piglets.

\begin{tabular}{|c|c|c|c|c|c|}
\hline Item & Control & FOS & Allergy & R-MSE & $p$-Value \\
\hline Average daily gain $(\mathrm{g} / \mathrm{d})$ & $234.51 \pm 30.47^{a}$ & $236.08 \pm 46.19^{a}$ & $180.45 \pm 31.40^{b}$ & 16.43 & 0.034 \\
\hline Average daily feed intake $(\mathrm{g} / \mathrm{d})$ & $501.51 \pm 12.46$ & $525.71 \pm 56.46$ & $481.44 \pm 28.09$ & 17.30 & 0.084 \\
\hline$F / G$ & $2.20 \pm 0.23^{b}$ & $2.26 \pm 0.20^{b}$ & $2.73 \pm 0.49^{a}$ & 0.15 & 0.026 \\
\hline Occurrence of diarrhea (\%) & 0 & 8.75 & 22.5 & & \\
\hline Total serum lgG (mg/mL) & $16.95 \pm 2.80^{b}$ & $20.58 \pm 2.42^{a}$ & $21.34 \pm 1.84^{\mathrm{a}}$ & 2.08 & 0.014 \\
\hline Total serum lgE ( $\mu \mathrm{g} / \mathrm{mL})$ & $110.58 \pm 12.59^{b}$ & $154.54 \pm 7.06^{a}$ & $158.45 \pm 19.37^{a}$ & 11.39 & 0.006 \\
\hline Glycinin specific IgG OD units & $0.656 \pm 0.027^{b}$ & $0.631 \pm 0.062^{b}$ & $0.727 \pm 0.047^{a}$ & 0.033 & 0.042 \\
\hline$\beta$-Conglycinin specific lgG OD units & $0.609 \pm 0.057^{b}$ & $0.525 \pm 0.049^{b}$ & $0.702 \pm 0.085^{a}$ & 0.037 & 0.005 \\
\hline \multicolumn{6}{|c|}{ Cytokine concentrations in serum (pg/mL) } \\
\hline IFN- $\gamma$ & $566.03 \pm 41.12^{a}$ & $529.60 \pm 30.51^{a}$ & $453.78 \pm 24.12^{b}$ & 20.01 & 0.01 \\
\hline IL-4 & $292.95 \pm 10.76^{b}$ & $278.01 \pm 11.32^{b}$ & $349.78 \pm 15.32^{a}$ & 11.19 & $<0.01$ \\
\hline IL-10 & $106.27 \pm 31.70^{b}$ & $153.36 \pm 44.66^{b}$ & $260.09 \pm 82.55^{a}$ & 25.58 & $<0.01$ \\
\hline IL-6 & $61.75 \pm 10.81$ & $62.75 \pm 7.88$ & $66.00 \pm 6.67$ & 42.06 & 0.451 \\
\hline TNF- $\alpha$ & $44.81 \pm 16.61$ & $50.33 \pm 7.85$ & $53.83 \pm 16.94$ & 7.81 & 0.342 \\
\hline
\end{tabular}

${ }^{a}$ Each value is the mean of data from five piglets (average initial BW of $6.81 \pm 0.58 \mathrm{~kg}$ ) per group.

${ }^{b}$ Diarrhea (\%) $=($ Number of diarrhea pigs $\times$ Days of diarrhea $) /($ Total number of pigs $\times$ Total number of text days $) \times 100 \%$.

Dissimilar letters represent significant difference among different groups $(p<0.05)$

sources. However, the allergy diet contained peeled soybean meal (30\%), soybean (5\%), and bran (1.30\%) as protein sources. Zeolite is inert and does not react chemically with food or body fluids. Therefore, it is commonly used as a vector for premix. In this study, the control diet and the allergy diet contained $0.8 \%$ zeolite, whereas the FOS diet contained $0.6 \%$ FOS instead of zeolite.

\section{Experimental Protocol and Sample Collection}

After 7 days of adaptation, the piglets were treated at 28 days of age. The piglets in allergy group and FOS group were sensitized for the first 10 days by feeding allergy diet and subsequently boosted by feeding allergy diet on days 16-18 and on days 3132. The control diet was given on all the other days. The piglets had free access to food and water and were weighed at the start and the end of the trial (day 0 and day 32 ) to calculate the average daily weight gain.

The blood samples were obtained from each piglet by vena cava puncture using $10 \mathrm{~mL}$ gel vacuum collective tubes on days 10,25 , and 32 . These blood samples were taken at a $3 \mathrm{~h}$ interval after feeding the allergy diet, incubated for $30 \mathrm{~min}$ at $37^{\circ} \mathrm{C}$, and then centrifuged for $20 \mathrm{~min}$ at $2,000 \mathrm{rpm} / \mathrm{min}$. The supernatant was collected and stored at $-80^{\circ} \mathrm{C}$ for measurements of immunoglobulin and cytokine levels.

At day 32, three piglets from each group were chosen randomly and euthanized. The contents of four intestinal segments including middle of jejunum (M-jejunum), posterior of jejunum (P-jejunum), ileum, and cecum were collected. These samples were snap freezing in liquid nitrogen and stored at $-80^{\circ} \mathrm{C}$ until use.

\section{Analysis of Total Serum IgG, IgE, and Specific IgG Levels by ELISA}

Total serum IgG and IgE antibody levels were determined by using swine ELISA kits (Lengtonbio, China) according to the manufacturer's instructions. Glycinin-specific IgG and $\beta$-conglycinin-specific IgG antibody levels were determined by using an indirect ELISA as previously described by Sun et al. (2008). The 96-well microplates (Corning-Costar, United States) were coated with $10 \mu \mathrm{g} / \mathrm{mL}$ glycinin in carbonate buffer $(\mathrm{pH}=9.6)$ at $4^{\circ} \mathrm{C}$ overnight. The plates were washed three times and blocked with bovine serum albumin blocking solution (2\%). Swine serum (appropriately diluted) was added and incubated with biotinylated antipig IgG and horseradish peroxidase conjugates (Abcam, United Kingdom). After wash, the color reagent and stop solution were added and the optical density (OD) was measured at $450 \mathrm{~nm}$. The IgG value was calculated based on the standard curve and dilution factors.

\section{Analysis of Cytokine Levels by ELISA}

Concentrations of interleukin 4 (IL-4), IL-6, IL-10, interferon- $\gamma$ (IFN- $\gamma$ ), and tumor necrosis factor- $\alpha$ (TNF- $\alpha)$ in serum were determined using the swine enzyme-linked immunosorbent assay kit (Abcam, United Kingdom) according to the manufacturer's instructions.

\section{Gene Sequencing of 16S rRNA of Gut Microbes}

The microbial genomic DNA was extracted from intestinal content samples using Fast DNA SPIN extraction kits (MP Biomedicals, Santa Ana, CA, United States) according to the manufacturer's instructions. The quantity and quality of extracted DNAs were measured using a NanoDrop ND-1000 spectrophotometer (Thermo Fisher Scientific, Waltham, MA, United States) and agarose gel electrophoresis, respectively. In this experiment, the microbes' V3-V4 hypervariable regions of $16 \mathrm{~S}$ rRNA gene, with a length of approximately $500 \mathrm{bp}$, were used for sequencing. The primer sequences were $338 \mathrm{~F} \quad 5^{\prime}$-ACTCCTACGGGAGGCAGCA-3' and 806R $5^{\prime}$-GGACTACHVGGGTWTCTAAT-3'. The polymerase chain 
TABLE 3 | The bacterial diversity of the intestinal content samples based on Miseq of the 16S rRNA gene.

(A) The comparison among four intestinal segments-ignored groups.

\begin{tabular}{|c|c|c|c|c|}
\hline & M-Jejunum & P-Jejunum & Ileum & Cecum \\
\hline Chao1 & $1279.08 \pm 197.92^{b}$ & $1419.47 \pm 144.14^{b}$ & $1425.42 \pm 300.40^{b}$ & $1721.15 \pm 286.64^{a}$ \\
\hline Ace & $1287.90 \pm 181.72^{b}$ & $1442.22 \pm 158.27^{b}$ & $1439.30 \pm 307.76^{b}$ & $1754.34 \pm 296.62^{\mathrm{a}}$ \\
\hline Shannon & $6.918 \pm 0.436^{b}$ & $7.327 \pm 0.520^{a b}$ & $7.614 \pm 0.439^{a}$ & $7.826 \pm 0.348^{a}$ \\
\hline Simpson & $0.9556 \pm 0.019^{b}$ & $0.966 \pm 0.013^{a b}$ & $0.975 \pm 0.006^{a}$ & $0.970 \pm 0.012^{a}$ \\
\hline
\end{tabular}

(B) The comparison among three groups in each intestinal segment.

\begin{tabular}{|c|c|c|c|}
\hline & Control & $0.6 \%$ FOS & Allergy \\
\hline \multicolumn{4}{|c|}{ M-jejunum } \\
\hline Chao1 & $1200.42 \pm 297.38$ & $1370.15 \pm 150.19$ & $1266.67 \pm 154.11$ \\
\hline Ace & $1218.92 \pm 262.77$ & $1378.12 \pm 138.80$ & $1266.67 \pm 154.11$ \\
\hline Shannon & $6.777 \pm 0.434$ & $7.000 \pm 0.701$ & $6.977 \pm 0.188$ \\
\hline Simpson & $0.954 \pm 0.019$ & $0.957 \pm 0.007$ & $0.956 \pm 0.032$ \\
\hline \multicolumn{4}{|c|}{ P-Jejunum } \\
\hline Chao1 & $1463.44 \pm 109.93$ & $1418.74 \pm 92.46$ & $1376.22 \pm 238.26$ \\
\hline Ace & $1490.42 \pm 103.46$ & $1433.72 \pm 100.94$ & $1402.52 \pm 270.82$ \\
\hline Shannon & $7.21 \pm 0.632$ & $7.16 \pm 0.651$ & $7.61 \pm 0.271$ \\
\hline Simpson & $0.961 \pm 0.013$ & $0.974 \pm 0.003$ & $0.964 \pm 0.019$ \\
\hline \multicolumn{4}{|l|}{ Ileum } \\
\hline Chao1 & $1247.22 \pm 144.30^{b}$ & $1506.36 \pm 114.69^{a}$ & $1716.35 \pm 52.28^{a}$ \\
\hline Ace & $1260 \pm 153.69^{b}$ & $1508.21 \pm 114.66^{a}$ & $1744.70 \pm 79.92^{a}$ \\
\hline Shannon & $7.123 \pm 0.065^{b}$ & $7.89 \pm 0.29^{a}$ & $7.83 \pm 0.372^{a}$ \\
\hline Simpson & $0.972 \pm 0.006$ & $0.976 \pm 0.011$ & $0.974 \pm 0.006$ \\
\hline \multicolumn{4}{|l|}{ Cecum } \\
\hline Chao1 & $1732.15 \pm 275.23$ & $1701.28 \pm 249.15$ & $1730.02 \pm 435.82$ \\
\hline Ace & $1809.87 \pm 281.42$ & $1739.30 \pm 314.97$ & $1713.85 \pm 407.56$ \\
\hline Shannon & $7.467 \pm 0.137^{\mathrm{C}}$ & $8.193 \pm 0.138^{a}$ & $7.817 \pm 0.227^{b}$ \\
\hline Simpson & $0.960 \pm 0.015$ & $0.979 \pm 0.001$ & $0.972 \pm 0.006$ \\
\hline
\end{tabular}

Dissimilar letters represent significant difference among different groups $(p<0.05)$.

reaction (PCR) condition was as follows: initial denaturation at $98^{\circ} \mathrm{C}$ for $2 \mathrm{~min}$, followed by 25 cycles consisting of denaturation at $98^{\circ} \mathrm{C}$ for $15 \mathrm{~s}$, annealing at $55^{\circ} \mathrm{C}$ for $30 \mathrm{~s}$, and extension at $72^{\circ} \mathrm{C}$ for $30 \mathrm{~s}$, with a final extension of $5 \mathrm{~min}$ at $72^{\circ} \mathrm{C}$. The PCR amplicons were purified with Agencourt AMPure Beads (Beckman Coulter, Indianapolis, IN, United States) and quantified using the PicoGreen dsDNA Assay Kit (Invitrogen, Carlsbad, CA, United States). After that, the individual quantification steps were pooled in equal amounts paired-end $2 \mathrm{bp} \times 250 \mathrm{bp}$ sequencing was performed using the Illumina MiSeq platform with MiSeq Reagent Kit v3 at Shanghai Personal Biotechnology, Co., Ltd. (Shanghai, China).

\section{Analysis of Biodiversity}

Illumina MiSeq sequences were analyzed by Quantitative Insights Into Microbial Ecology, v1.8.0 (QIIME) (Caporaso et al., 2010) for taxonomic analysis at phylum and genus levels. The operational taxonomy units (OTUs) were defined as sequences clustered with a similarity cutoff of $97 \%$ using UCLUST algorithm (Edgar et al., 2011). Alpha diversity indices were determined using Mothur (Schloss et al., 2009).

\section{Statistical Analysis}

The data of immune indices were presented as mean \pm standard deviation and analyzed using one-way analysis of variance (oneway ANOVA), followed by LSD multiple comparison tests by SPSS software (IBM SPSS Statistics 20 for windows). The value of $p<0.05$ was considered statistically significant. Canonical correspondence analysis (CCA) was performed using Canoco for Windows 4.5 between the first 20 predominant genera and the immune indices in each group. Correlation analysis between key communities and immune indices were determined based on Pearson's rank correlation coefficient.

\section{RESULTS}

\section{Performance and Occurrence of Diarrhea}

The performance and occurrence of diarrhea are shown in Table 2. Piglets sensitized with soybeans had lower average daily gain and feed conversion ratio $(p<0.05)$ compared with the control group. However, supplementation with FOS increased the daily weight gain reaching values similar 


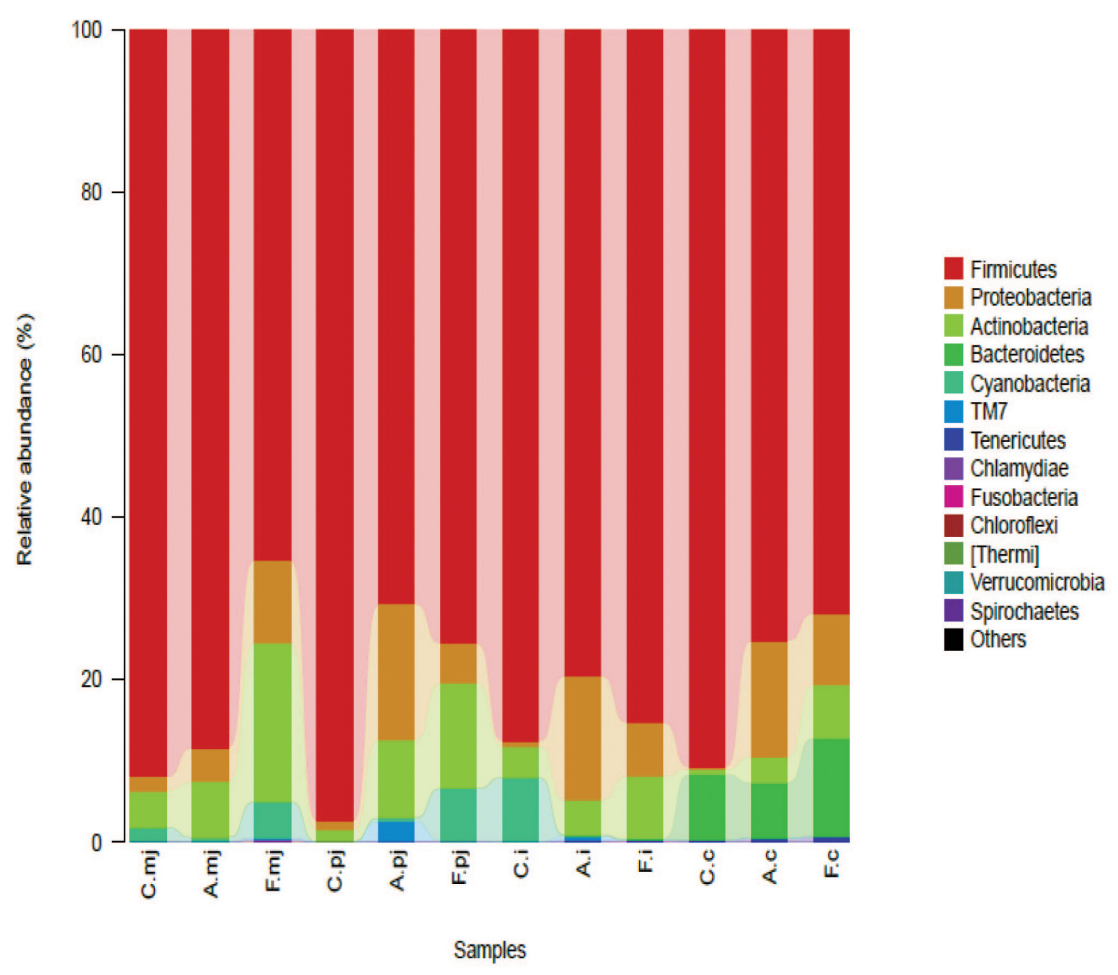

FIGURE 1 | Bacterial compositions in the different groups and intestinal segments at the phylum level.

TABLE 4 | Profiles of gut microbes in all intestinal segments and groups at the rank of phylum according to taxon-based analysis.

\begin{tabular}{|c|c|c|c|c|c|}
\hline & Firmicutes (\%) & Proteobacteria (\%) & Cyanobacteria (\%) & Actinobacteria (\%) & Bacteroidetes (\%) \\
\hline C-mj & $91.99 \pm 1.34^{\mathrm{a}}$ & $1.71 \pm 2.66^{b}$ & $1.72 \pm 1.66$ & $4.52 \pm 1.78^{b}$ & $0.01 \pm 0.01$ \\
\hline A-mj & $88.45 \pm 8.21^{a}$ & $4.14 \pm 1.89^{a}$ & $0.50 \pm 0.55$ & $6.87 \pm 9.51^{b}$ & $0.01 \pm 0.01$ \\
\hline F-mj & $65.21 \pm 3.65^{b}$ & $10.18 \pm 5.47^{a}$ & $4.44 \pm 3.71$ & $19.64 \pm 8.44^{a}$ & $0.03 \pm 0.003$ \\
\hline C-pj & $97.52 \pm 2.47^{a}$ & $1.06 \pm 1.52^{b}$ & $0.01 \pm 0.01^{b}$ & $1.42 \pm 1.06$ & $0.00 \pm 0.00$ \\
\hline A-pj & $70.68 \pm 14.11^{b}$ & $16.67 \pm 7.25^{a}$ & $0.42 \pm 0.70^{b}$ & $9.69 \pm 15.49$ & $0.04 \pm 0.05$ \\
\hline F-pj & $75.55 \pm 12.92^{b}$ & $4.92 \pm 3.13^{b}$ & $6.45 \pm 11.10^{\mathrm{a}}$ & $12.91 \pm 10.88$ & $0.05 \pm 0.06$ \\
\hline C-i & $87.61 \pm 0.51$ & $0.59 \pm 0.11^{b}$ & $7.91 \pm 0.51^{a}$ & $3.87 \pm 0.48$ & $0.01 \pm 0.00$ \\
\hline$A-i$ & $79.58 \pm 7.39$ & $15.19 \pm 5.16^{a}$ & $0.06 \pm 0.05^{b}$ & $4.37 \pm 5.98$ & $0.15 \pm 0.16$ \\
\hline$F-i$ & $85.28 \pm 12.01$ & $6.61 \pm 7.50^{b}$ & $0.06 \pm 0.07^{b}$ & $7.73 \pm 10.84$ & $0.13 \pm 0.23$ \\
\hline $\mathrm{C}-\mathrm{C}$ & $90.82 \pm 6.42^{\mathrm{a}}$ & $0.28 \pm 0.14^{b}$ & $0.02 \pm 0.02$ & $0.60 \pm 0.44$ & $8.09 \pm 6.62$ \\
\hline$A-C$ & $75.23 \pm 7.22^{b}$ & $14.35 \pm 0.19^{a}$ & $0.05 \pm 0.07$ & $3.15 \pm 1.98$ & $6.80 \pm 4.93$ \\
\hline $\mathrm{F}-\mathrm{C}$ & $71.92 \pm 5.76^{b}$ & $8.74 \pm 2.40^{a}$ & $0.03 \pm 0.01$ & $6.57 \pm 3.39$ & $12.13 \pm 7.01$ \\
\hline
\end{tabular}

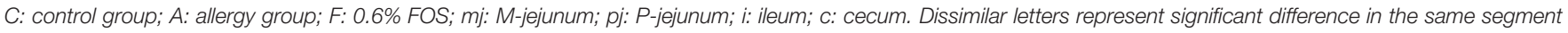
among different groups $(p<0.05)$.

to the control group. Furthermore, occurrence of diarrhea decreased in the FOS group (8.75\%), compared with the allergy group (22.50\%).

\section{Total Serum IgG and IgE and Specific IgG Levels}

To explore the effects of FOS on soybean-induced allergy in sensitized pigs, the total serum IgG, IgE, glycinin-specific IgG, and $\beta$-conglycinin-specific IgG levels were determined (Table 2). The total serum IgG and IgE were significantly higher in the allergy group and the FOS group compared with the control group $(p<0.05)$. Glycinin-specific IgG and $\beta$-conglycininspecific IgG were significantly higher in the allergy group compared with the control group $(p<0.05)$; however, no differences were observed between the FOS group and the control group.

\section{Serum Cytokine Levels}

To determine whether oral FOS administration altered Th1/Th2 cytokine levels in response to soybean stimulation, serum IL-4,IL-10, and IFN- $\gamma$ levels were measured. The 


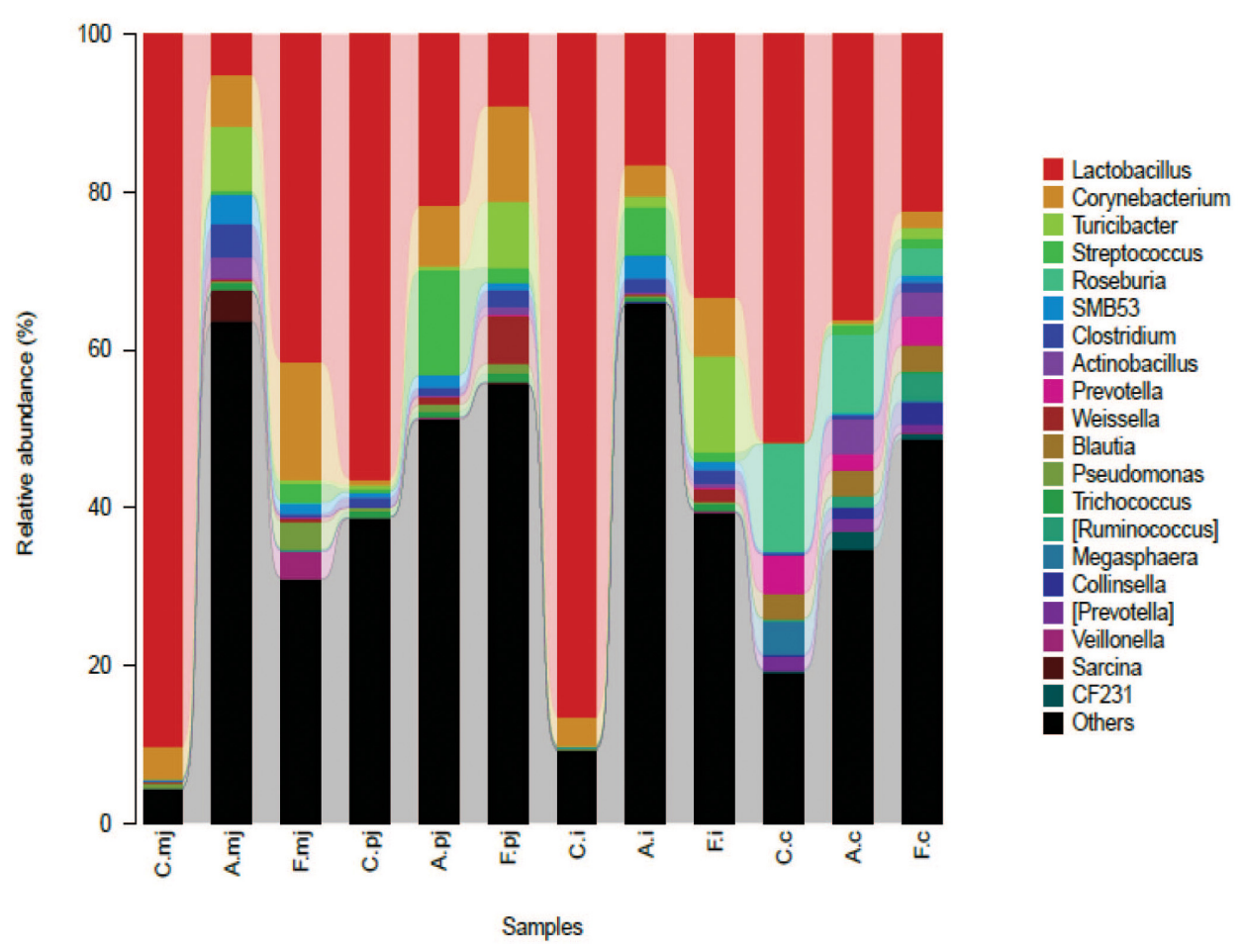

FIGURE 2 | Bacterial compositions in the different groups and intestinal segments at the genus level.

TABLE 5 | Dominance of gut microbes in all intestinal segments and groups at the rank of genus according to taxon-based analysis.

\begin{tabular}{|c|c|c|c|c|c|c|}
\hline & Lactobacillus (\%) & Clostridiaceae (\%) & Turicibacter (\%) & Streptococcus (\%) & Peptostreptococcaceae (\%) & Bifidobacteria (\%) \\
\hline C-mj & $90.39 \pm 2.34^{a}$ & $0.478 \pm 0.36^{b}$ & $0.02 \pm 0.002^{b}$ & $0.05 \pm 0.01$ & $0.04 \pm 0.06$ & $0.14 \pm 0.06^{b}$ \\
\hline A-mj & $5.06 \pm 2.15^{c}$ & $53.88 \pm 7.49^{a}$ & $8.07 \pm 6.67^{a}$ & $0.52 \pm 0.09$ & $4.99 \pm 2.20$ & $0.05 \pm 0.07^{b}$ \\
\hline F-mj & $41.48 \pm 17.6^{b}$ & $7.46 \pm 8.89^{b}$ & $0.461 \pm 0.36^{b}$ & $2.30 \pm 1.80$ & $0.72 \pm 0.80$ & $3.59 \pm 4.68^{a}$ \\
\hline C-pj & $56.39 \pm 6.52^{\mathrm{a}}$ & $0.33 \pm 0.07^{\mathrm{c}}$ & $0.032 \pm 0.03^{b}$ & $0.36 \pm 0.62^{b}$ & $0.03 \pm 0.02^{b}$ & $0.05 \pm 0.07$ \\
\hline A-pj & $21.64 \pm 15.28^{b}$ & $36.10 \pm 11.53^{a}$ & $1.39 \pm 0.69^{b}$ & $13.27 \pm 14.63^{a}$ & $8.85 \pm 1.70^{\mathrm{a}}$ & $0.33 \pm 0.54$ \\
\hline F-pj & $8.97 \pm 6.05^{b}$ & $20.53 \pm 15.11^{b}$ & $12.33 \pm 7.64^{\mathrm{a}}$ & $1.81 \pm 2.57^{\mathrm{b}}$ & $8.08 \pm 3.99^{a}$ & $0.41 \pm 0.13$ \\
\hline$C-i$ & $86.65 \pm 0.32^{a}$ & $28.08 \pm 4.51$ & $0.59 \pm 0.66^{b}$ & $0.05 \pm 0.02^{b}$ & $6.45 \pm 6.21^{a}$ & $0.05 \pm 0.00$ \\
\hline$A-i$ & $16.42 \pm 9.19^{b}$ & $23.50 \pm 17.21$ & $0.59 \pm 0.94^{b}$ & $6.00 \pm 3.92^{a}$ & $2.38 \pm 2.64^{b}$ & $0.08 \pm 0.09$ \\
\hline$F-i$ & $33.16 \pm 26.76^{b}$ & $34.15 \pm 1.85$ & $8.47 \pm 8.22^{a}$ & $1.07 \pm 1.34^{b}$ & $8.08 \pm 6.32^{a}$ & $0.07 \pm 0.10$ \\
\hline $\mathrm{C}-\mathrm{C}$ & $51.73 \pm 9.33^{a}$ & $0.96 \pm 0.75$ & $0.08 \pm 0.11$ & $0.01 \pm 0.02$ & $0.21 \pm 0.26$ & $0.00 \pm 0.00$ \\
\hline$A-C$ & $36.21 \pm 17.1^{\mathrm{ab}}$ & $1.73 \pm 0.54$ & $0.23 \pm 0.08$ & $1.09 \pm 0.66$ & $0.68 \pm 0.31$ & $0.00 \pm 0.01$ \\
\hline $\mathrm{F}-\mathrm{C}$ & $22.51 \pm 15.3^{b}$ & $4.95 \pm 3.86$ & $1.32 \pm 1.15$ & $1.12 \pm 0.48$ & $1.28 \pm 0.91$ & $0.05 \pm 0.05$ \\
\hline
\end{tabular}

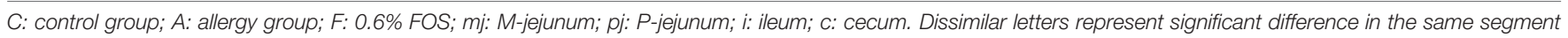
among different groups $(p<0.05)$.

results showed that IFN- $\gamma$ level was significantly higher $(p<0.05)$, while IL-4 and IL-10 levels were significantly lower in the control and FOS groups compared with the allergy group $(p<0.05)$. There were no differences for IL-6 and TNF- $\alpha$ among different groups $(p>0.05)$ (Table 2).

\section{Analysis of Gut Microbes}

A total of 1,282,521 sequences were obtained from the piglets gut microbes, with an average of 35,626 sequences per sample (30, 230-60, 640 sequences). The bacterial diversity of the intestinal content samples in different groups is presented in Table 3. The Chao 1 and Ace indices in cecum were significantly higher than in other intestinal segments $(p<0.05)$ (Table 3A). The M-jejunum had lower Shannon and Simpson than ileum and cecum $(p<0.05)$. As shown in Table 3B, Chao1, ACE, and Shannon of ileum in the FOS and allergy groups were significantly higher compared with the control group $(p<0.05)$. The Shannon indices ranged from 6.777 to 8.193 in three groups, respectively. There were no statistically significant differences in diversity estimators between $\mathrm{M}$-jejunum and $\mathrm{P}$-jejunum $(p>0.05)$. 

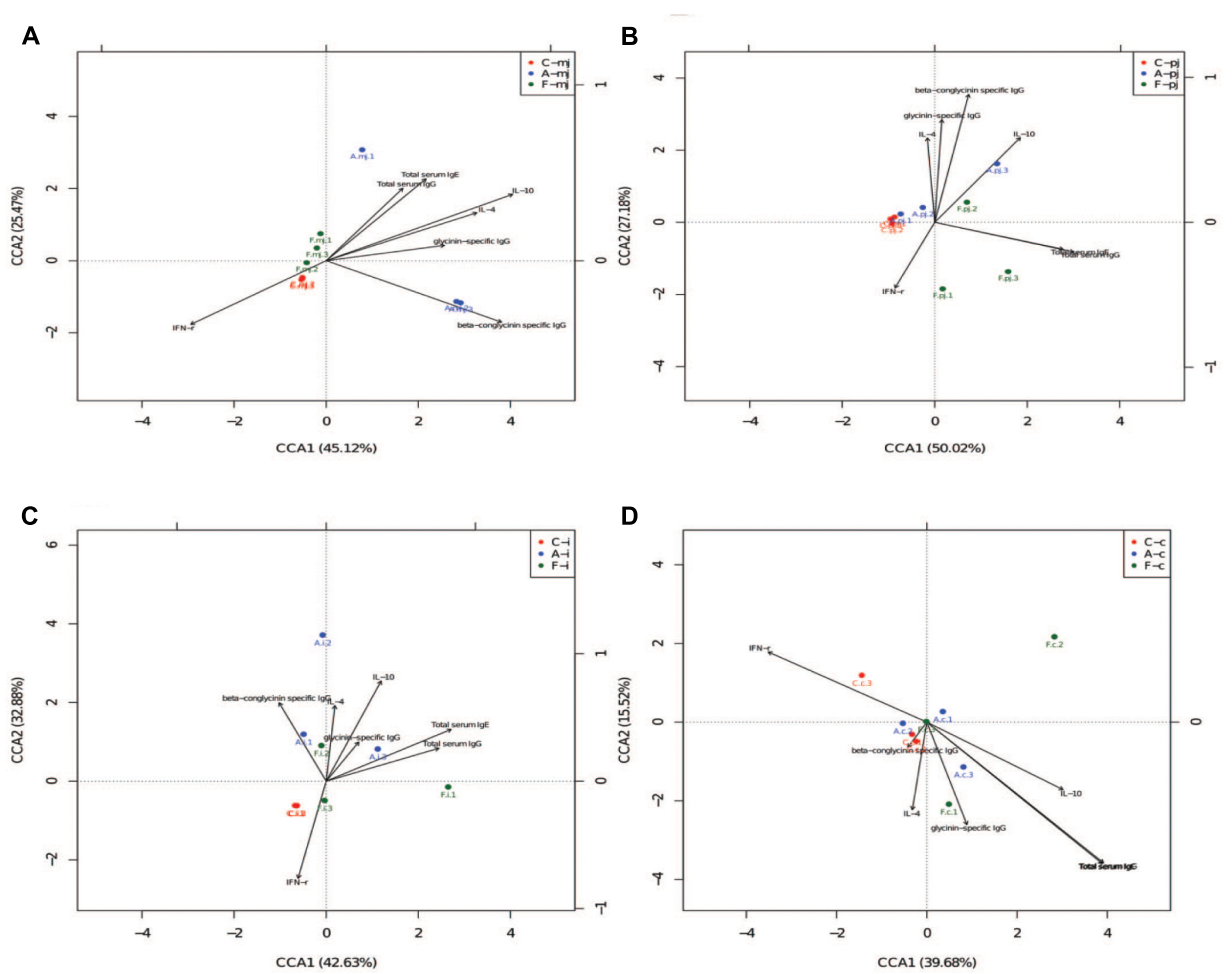

FIGURE 3 | The CCA of all intestinal segments between immune index and first 20 species of bacteria at genus level. (A) M-jejunum; (B) P-jejunum; (C) ileum (D) cecum. "•" indicates the first 20 species of bacteria genus of each group. Arrow indicates immune index. The closer the pendulum is to the arrow, the greater the positive correlation between bacteria genus and the immune index; the pendulum is farther away from the arrow, which indicates negative correlation between bacteria genus and the immune index. If the angle between the arrows is acute, immune indexes were a positive correlation; the converse indicated negative correlation.

At the phylum level, Firmicutes was the most-dominant phylum among all intestinal segments, followed by Proteobacteria, Actinobacteria, Cyanobacteria, and Bacteroidetes (Figure 1). For P-jejunum and cecum, the abundance of Firmicutes in the allergy group was significantly lower compared with the control group ( $p<0.05$ ) (Table 4). In contrast, the ratio of Proteobacteria was significantly higher in the allergy group than the control group in all intestinal segments. Compared to the control and allergy groups, Proteobacteria showed a dynamic pattern in the FOS group: a $10.18 \%$ of increase at $\mathrm{M}$-jejunum, a $4.92 \%$ of decrease at P-jejunum, and a $6.61 \%$ of decrease at ileum, and an $8.74 \%$ of increase at cecum. Cyanobacteria in ileum was significantly lower in the allergy group than in the control group. Actinobacteria in M-jejunum was significantly higher in the FOS group than the allergy and control groups $(p<0.05)$. The abundance of Bacteroidetes increased more than 7-10-fold at cecum than other segments.

At the genus level, a total of 183 genera were identified from all samples. The abundance of Lactobacillus made it the mostdominant bacterium in all genus (Figure 2) and was significantly lower in the allergy group at $\mathrm{M}$-jejunum, $\mathrm{P}$-jejunum, and ileum than the control group $(p<0.05)$ (Table 5). The abundance of Lactobacillus at cecum was $51.73 \%$ in the control group and $36.21 \%$ in the allergy group. However, there was no significant difference between these two groups $(p>0.05)$. Compared to the allergy group, Lactobacillus showed a dynamic pattern in the FOS group with a $41.48 \%$ of increase at M-jejunum, an $8.97 \%$ of decrease at P-jejunum, a $33.16 \%$ of increase at ileum, and a $22.51 \%$ of decrease at cecum. Bifidobacteria is a minor community in intestinal microbes, which was enriched in the FOS group in M-jejunum. The abundance of Streptococcus was significantly higher in the allergy group at P-jejunum and ileum $(p<0.05)$. Moreover, Clostridiaceae was significantly higher in the allergy group at $\mathrm{M}$-jejunum and $\mathrm{P}$-jejunum compared to the control group $(p<0.05)$, whereas it was significantly decreased in the FOS group compared with the allergy group. In addition, Turicibacter, Peptostreptococcaceae also changed as shown in Table 5.

\section{Correlation Analysis Between Immune Indices and Gut Microbes}

Canonical correspondence analysis reflects the relationship between microbes and environmental factors (immune indices). As shown in Figure 3, we found that specific IgG, IL-4, IL10 , and total serum IgG and IgE were correlated negatively to IFN- $\gamma$. Microbes in the allergy group were correlated positively to specific IgG, IL-4, and IL-10 and were correlated negatively to IFN- $\gamma$. Microbes in the control group were correlated positively 
TABLE 6 | Phyla correlated to the key communities of intestinal flora and Pearson's correlation between phyla and immune index.

\begin{tabular}{|c|c|c|c|c|c|c|c|}
\hline Genus & $\begin{array}{l}\text { Total serum } \\
\text { IgG Pearson's } \\
\text { correlation }\end{array}$ & $\begin{array}{c}\beta \text {-Conglycinin } \\
\text { specific IgG } \\
\text { Pearson's } \\
\text { correlation }\end{array}$ & $\begin{array}{l}\text { Glycinin-specific } \\
\text { IgG Pearson's } \\
\text { correlation }\end{array}$ & $\begin{array}{l}\text { Total serum } \\
\text { IgE Pearson's } \\
\text { correlation }\end{array}$ & $\begin{array}{c}\text { IL-4 } \\
\text { Pearson's } \\
\text { correlation }\end{array}$ & $\begin{array}{c}\text { IFN- } \gamma \\
\text { Pearson's } \\
\text { correlation }\end{array}$ & $\begin{array}{c}\text { IL-10 } \\
\text { Pearson's } \\
\text { correlation }\end{array}$ \\
\hline \multicolumn{8}{|l|}{ M-jejunum } \\
\hline Firmicutes & -0.628 & $0.729 *$ & 0.517 & -0.566 & 0.482 & -0.999 & 0.144 \\
\hline Proteobacteria & 0.485 & -0.237 & -0.273 & 0.410 & -0.367 & -0.236 & 0.100 \\
\hline Actinobacteria & 0.519 & $-0.691^{*}$ & -0.498 & 0.481 & -0.372 & 0.139 & -0.152 \\
\hline Bacteroidetes & 0.04 & -0.285 & -0.609 & -0.033 & -0.558 & 0.022 & -0.185 \\
\hline Cyanobacteria & 0.347 & $-0.689 *$ & -0.217 & 0.330 & -0.340 & 0.402 & -0.328 \\
\hline \multicolumn{8}{|l|}{ P-Jejunum } \\
\hline Firmicutes & -0.595 & -0.455 & -0.242 & -0.575 & -0.198 & 0.537 & $-0.720^{*}$ \\
\hline Proteobacteria & 0.248 & 0.574 & 0.301 & 0.389 & $0.676^{*}$ & $-0.832^{*}$ & $0.713^{*}$ \\
\hline Actinobacteria & 0.584 & 0.183 & 0.095 & 0.459 & -0.043 & -0.006 & 0.341 \\
\hline Bacteroidetes & 0.348 & -0.262 & -0.431 & 0.283 & -0.095 & -0.112 & 0.073 \\
\hline Cyanobacteria & 0.031 & -0.177 & -0.228 & 0.022 & -0.464 & -0.131 & 0.025 \\
\hline \multicolumn{8}{|l|}{ Ileum } \\
\hline Firmicutes & -0.37 & -0.254 & $-0.822^{*}$ & -0.47 & -0.523 & 0.479 & -0.642 \\
\hline Proteobacteria & 0.339 & 0.408 & 0.514 & 0.460 & 0.555 & $-0.828^{*}$ & $0.83^{*}$ \\
\hline Actinobacteria & 0.487 & -0.170 & 0.377 & 0.517 & 0.052 & 0.084 & 0.120 \\
\hline Bacteroidetes & 0.655 & 0.065 & 0.620 & $0.700^{*}$ & 0.361 & -0.246 & 0.494 \\
\hline Cyanobacteria & $-0.813^{*}$ & -0.117 & -0.118 & $-0.898^{*}$ & -0.226 & 0.607 & $-0.683^{*}$ \\
\hline \multicolumn{8}{|l|}{ Cecum } \\
\hline Firmicutes & -0.559 & 0.229 & 0.482 & -0.455 & 0.34 & -0.073 & -0.011 \\
\hline Proteobacteria & 0.542 & 0.491 & 0.637 & $0.705^{*}$ & $0.701^{*}$ & $-0.824^{*}$ & 0.893* \\
\hline Actinobacteria & 0.537 & -0.152 & 0.251 & 0.598 & -0.082 & -0.259 & 0.343 \\
\hline Bacteroidetes & -0.063 & 0.203 & 0.210 & -0.072 & -0.139 & -0.326 & 0.144 \\
\hline Cyanobacteria & 0.320 & 0.523 & $0.702 *$ & 0.234 & 0.331 & -0.321 & 0.533 \\
\hline
\end{tabular}

* The correlation is significant at a level of 0.05 .

to IFN- $\gamma$. Microbes in the FOS group were correlated positively to total serum IgG and IgE.

We also performed an association analysis based on the Pearson's rank correlation coefficient using different taxa by pooling these three groups together. At the phylum level (Table 6), Firmicutes was correlated positively to the level of $\beta$-conglycinin-specific IgG in M-jejunum and was correlated negatively to the level of IL-10 in P-jejunum and glycinin-specific $\operatorname{IgG}$ in ileum $(p<0.05)$. Proteobacteria was correlated positively to the expression of IL-4 in P-jejunum and cecum and the level of IL-10 in P-jejunum, ileum, and cecum $(p<0.05)$; it was correlated negatively to the expression of IFN- $\gamma$ in P-jejunum, ileum, and cecum $(p<0.05)$. Actinobacteria and Cyanobacteria were correlated negatively to the expression of $\beta$-conglycininspecific IgG in M-jejunum $(p<0.05)$. Cyanobacteria was correlated negatively to the level of total serum IgG, IgE, and IL-10 in ileum $(p<0.05)$.

At the genus level (Table 7), Lactobacillus was correlated negatively to total serum IgG, IgE, and IL-10 and was correlated positively to IFN- $\gamma$ in all intestinal segments. Clostridiaceae, Peptostreptococcaceae, and Enterobacteriaceae were correlated positively to the expression of $\beta$-conglycinin-specific IgG, IL4 , and IL-10 $(p<0.05)$ and were correlated negatively to the level of IFN- $\gamma$ in M-jejunum $(p<0.05)$. Clostridiaceae and Peptostreptococcaceae were correlated positively to the level of
IL-10 $(p<0.05)$ and were correlated negatively to IFN- $\gamma$ in ileum. Enterobacteriaceae was correlated positively to $\beta$-conglycininspecific IgG, glycinin-specific IgG, IL-4, and IL-10 $(p<0.05)$ and correlated negatively to IFN- $\gamma(p<0.05)$ in cecum. Streptococcus was correlated positively to glycinin and $\beta$-conglycinin-specific IgG and IL-10 in P-jejunum $(p<0.05)$. Total serum IgG and IgE were correlated positively to Peptostreptococcaceae, Turicibacter, Streptococcus, Clostridiales, and Clostridium in all intestinal segments.

\section{DISCUSSION}

Soybean antigen protein (particularly glycinin and $\beta$-conglycinin) often impairs the performance and immune function of swine (Sun et al., 2008, 2009), such as average daily gain and feed conversion, and causes diarrhea, which is similar to the findings in our study. We also found that $0.6 \%$ FOS enhanced the performance of swine and reduced the occurrence of diarrhea, which is consistent with previous studies (Oli et al., 1998; Estrada et al., 2001; Nakamura et al., 2010; Apper et al., 2016).

Previous studies have shown that soybean antigen-induced anaphylaxis mainly includes IgE-mediated type I allergic reaction and IgG-mediated type IV allergic reaction (Sun 
TABLE 7 | Genera correlated to the key communities of intestinal flora and Pearson's correlation between genus and immune index.

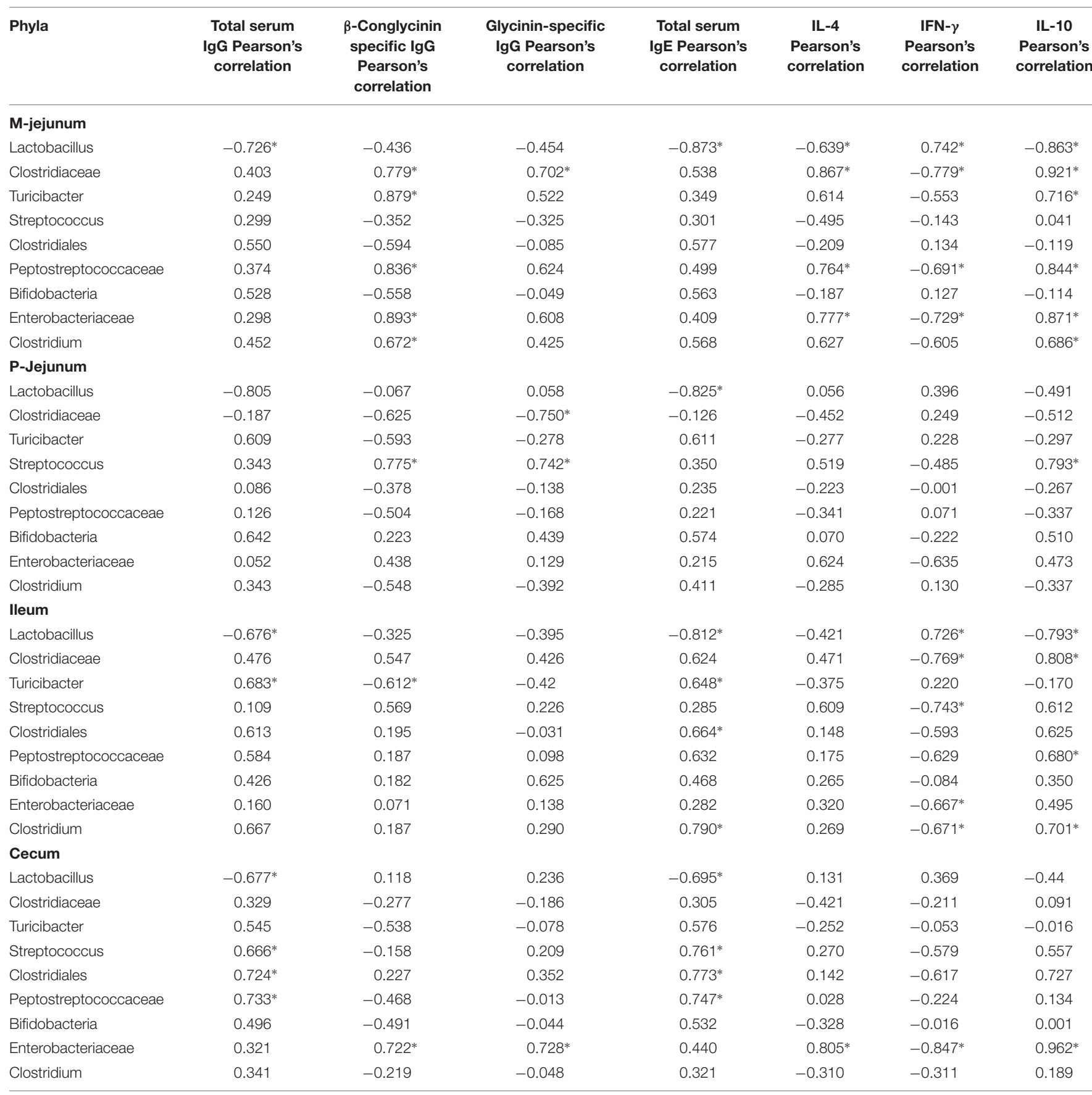

*The correlation is significant at a level of 0.05 .

et al., 2008). Glycinin and $\beta$-conglycinin play an important role in the majority of soybean-induced anaphylaxis. The levels of glycinin and $\beta$-conglycinin-specific IgG were increased after the soybean-induced anaphylaxis (Burks et al., 1988). Similarly, a previous study also showed that soybean extracts increased soybean antigen-specific IgG level in the serum of infants with allergies, which were confirmed in our study. Furthermore, we found that glycinin and $\beta$-conglycininspecific IgG levels decreased in the FOS group; so, we speculated that FOS may suppress the specific IgG antibody by modulating gut microbes and then alleviate soybeaninduced anaphylaxis. In this study, we used biotinylated antipig IgG due to the lack of antipig IgE antibody, which has limited the unequivocal identification of antigen-specific IgE in sensitized pigs.

In addition, total serum IgG and IgE antibody levels were increased in the allergy group, which were similar to the findings from other studies (Friesen et al., 1993; Sun et al., 
2009; Yang et al., 2018). Previous studies have shown that FOS can enhance immunity by increasing total serum IgG in swine (Apper et al., 2016; Wang et al., 2017). Similarly, they were increased in FOS group compared with control group.

The analysis of serum cytokines showed that piglets with FOS supplementation had higher interferon- $\gamma$ level, but lower levels of IL- 4 and IL-10 compared with the allergy group. The IFN- $\gamma$ is a symbolic cytokine of Th1 cells. Inflammation factors of IL-4 and IL-10 are secreted by Th2 cells, which stimulate the proliferation of B lymphocytes and generate IgE and IgG antibodies (Yamada et al., 2012; Canani and Costanzo, 2013; Aldaghri et al., 2014), which play a key role in allergic inflammation (Prescott and Hogan, 2006). Vos et al. (2007) showed that GOS/FOS can reduce the Th2 response and increase the activation of Th1 pathway when Balb/c mice were sensitized with ovalbumin. These results suggest that the antihypersensitivity effect might be mediated by reversing the ratio of Th1/Th2 cells in the allergic subjects. In conclusion, suppressive effects of FOS on soybean antigen-induced anaphylaxis may be regulated by inflammatory factors and the balance between Th1 and Th2 immunity.

Gut microbes play a crucial role in the establishment of tolerance to food proteins. In this study, the microorganisms in the sensitized group changed significantly, indicating the damages to the intestinal microenvironment in piglets sensitized by soybeans. The phyla of Firmicutes and the genus of Lactobacillus were decreased in the allergy group. A previous study found a similar result that soybean antigen, such as $\beta$-conglycinin, can inhibit the proliferation of Lactobacillus and Bifidobacteria (Hao et al., 2010). Lactobacillus protects the host against potential pathogen invasions (Martín et al., 2013), promotes the mucosal immune response (Erickson and Hubbard, 2000), modulates the cytokine expression, and stimulates the production of $\operatorname{Tr} 1$ and Th3 cytokines (Smits et al., 2005; Frossard et al., 2007). It was reported that oral FOS affects intestinal microbes, especially the abundance of Lactobacillus and Bifidobacteria (Ohta et al., 2002; Langlands et al., 2004). Both Lactobacilli and Bifidobacteria have been shown to improve the increased gut permeability during the exposure to food allergens (Rautava et al., 2005). In the FOS group, Lactobacillus was higher in M-jejunum and ileum, whereas Bifidobacteria also increased in $\mathrm{M}$-jejunum. A recent research has shown that a chronic enrichment of Proteobacteria in the gut, including Enterobacteriaceae, can represent an imbalanced/unstable microbial community structure or a state of disease of the host (Shin et al., 2015). Proteobacteria are a major phylum of gram-negative bacteria, which can increase lipopolysaccharide endotoxin in the blood, decrease the number of intestinal barrier cells, and increase intestinal permeability, leading to chronic inflammatory response (Cani et al., 2007). In our study, Proteobacteria was significantly higher in the allergy group in all intestinal tracts and decreased in the FOS group at P-jejunum and ileum. Therefore, consumption of FOS might modulate the intestinal microbes, improve the gut permeability, and decrease the allergy reaction. We also observed
Turicibacter enrichment in the FOS group at P-jejunum and ileum. Similarly, supplementation of stachyose and barley malt can increase the relative abundance of Turicibacter (Zhong et al., 2015; Liu et al., 2018). Some pathogenic bacteria, including Streptococcus, can increase the levels of IL-6, IL-8, and IL-10 (Van den Bogert et al., 2014). Our study showed that Streptococcus was increased significantly in the allergy group and decreased in the FOS group at P-jejunum and ileum.

Studies show that microbes have modulatory effects on regulatory T-cells, which provides mutual benefits and regulations between the host immune system and microbes (Hrncir et al., 2008; Round and Mazmanian, 2010; Wei et al., 2010). We found that Lactobacillus was correlated negatively to the expression of IL-10 and total serum IgE and was correlated positively to the expression of IFN $-\gamma$. Previous studies reported that Lactobacillus suppressed T-cell proliferation and Th2 cytokines secretion from allergic objects (Von der Weid et al., 2001; Lin et al., 2006), inhibited IgE responses and systemic anaphylaxis in a murine model of food allergy (Shida et al., 2002), and enhanced IFN- $\gamma$ production (Pohjavuori et al., 2004). Proteobacteria promotes colonic inflammation (Maharshak et al., 2013) and induces IL-10 production (Devkota et al., 2012). We found that Proteobacteria and genus of Enterobacteriaceae were correlated positively to IL-4 and IL-10 and were correlated negatively to IFN- $\gamma$. Van et al. (2010) showed that FOS can promote immune function in swine by enhancing total serum IgG and IgE. The genus of Peptostreptococcaceae, Turicibacter, Streptococcus, Clostridiales, and Clostridium were correlated positively to total serum IgG and IgE.

\section{CONCLUSION}

Our study demonstrates that oral supplementation of FOS can effectively relieve anaphylaxis induced by the soybean antigen in piglets. This protective mechanism is associated with the suppression of specific IgG and inflammatory cytokine release as well as the change in gut microbes. Improvement of intestinal microbes is mainly indicated by the increase of Lactobacillus and Bifidobacteria in M-jejunum and the decrease in Proteobacteria in P-jejunum and ileum. In addition, FOS can increase the total serum $\operatorname{IgG}$ and $\operatorname{IgE}$ to enhance the immune function. Our results provide a new and effective solution for the alleviation of allergic symptoms in livestock and humans and provide new hope for the development of prebiotics for the prevention and treatment of allergic reactions.

\section{AUTHOR CONTRIBUTIONS}

MC and YZ designed and wrote this manuscript. $\mathrm{XZ}$ was involved in modifying the manuscript. GQ supervised the writing of this manuscript. All authors read and approved the final manuscript. 


\section{FUNDING}

This work was supported by National Natural Science Foundation of China (Grant Nos. 31572439 and

\section{REFERENCES}

Aldaghri, N. M., Alokail, M. S., Draz, H. M., Abdalrahman, S. H., Yakout, S. M., and Clerici, M. (2014). Th1/Th2 cytokine pattern in Arab children with severe asthma. Int. J. Clin. Exp. Med. 7, 2286-2291.

Alizadeh, A., Akbari, P., Difilippo, E., Schols, H. A., Ulfman, L. H., Schoterman, M. H., et al. (2016). The piglet as a model for studying dietary components in infant diets: effects of galacto-oligosaccharides on intestinal functions. Bri. J. Nutr. 115, 605-618. doi: 10.1017/S0007114515004997

Apper, E., Meymerit, C., Bodin, J. C., Respondek, F., and Wagner, A. (2016). Effect of dietary supplementation with short-chain fructooligosaccharides in lactating sows and newly weaned piglets on reproductive performance of sows, immune response and growth performance of piglets from birth to slaughter. J. Anim. Res. Nutr. 1:19. doi: 10.21767/2572-5459.100019

Burks, A. W., Brooks, J. R., and Sampson, H. A. (1988). Allergenicity of major component proteins of soybean determined by enzyme-linked immunosorbent assay (ELISA) and immunoblotting in children with atopic dermatitis and positive soy challenges. J. Allergy Clin. Immunol. 81, 1135-1142. doi: 10.1016/ 0091-6749(88)90881-0

Canani, R. B., and Costanzo, M. D. (2013). Gut microbiota as potential therapeutic target for the treatment of cow's milk allergy. Nutrients 5, 651-662. doi: 10.3390/ nu5030651

Cani, P. D., Amar, J., Iglesias, M. A., Poggi, M., Knauf, C., Bastelica, D., et al. (2007). Metabolic endotoxemia initiates obesity and insulin resistance. Diabetes Metab. Res. Rev. 56, 1761-1772. doi: 10.2337/db06-1491

Caporaso, J. G., Kuczynski, J., Stombaugh, J., Bittinger, K., Bushman, F. D., Costello, E. K., et al. (2010). QIIME allows analysis of high-throughput community sequencing data. Nat. Methods 7, 335-336. doi: 10.1038/nmeth. f.303

Cho, Y. S., Lee, J., Lee, T. H., Lee, E. Y., Lee, K. U., Park, J. Y., et al. (2004). AlphaLipoic acid inhibits airway inflammation and hyperresponsiveness in a mouse model of asthma. J. Allergy Clin. Immunol. 114, 429-435. doi: 10.1016/j.jaci. 2004.04.004

Cruchet, S., Obregon, M. C., Salazar, G., Diaz, E., and Gotteland, M. (2003). Effect of the ingestion of a dietary product containing Lactobacillus johnsonii La1 on helicobacter pylori colonization in children. Nutrition 19, 716-721. doi: 10.1016/S0899-9007(03)00109-6

De Cruz, P., Prideaux, L., Wagner, J., Ng, S. C., McSweeney, C., Kirkwood, C., et al. (2012). Characterization of the gastrointestinal microbiota in health and inflammatory bowel disease. Inflamm. Bowel Dis. 18, 372-390. doi: 10.1002/ibd. 21751

Delgado, G. T., Thomé, R., Gabriel, D. L., Tamashiro, W. M., and Pastore, G. M. (2012). Yacon (Smallanthussonchifolius)-derived fructooligosaccharides improves the immune parameters in the mouse. Nutr. Res. 32, 884-892. doi: 10.1016/j.nutres.2012.09.012

Devkota, S., Wang, Y., Musch, M., Leone, V., Fehlner-Peach, H., Nadimpalli, A., et al. (2012). Dietary-fat-induced taurocholic acid promotes pathobiont expansion and colitis in Il10-/- mice. Nature 487, 104-108. doi: 10.1038/ nature 11225

Edgar, R. C., Haas, B. J., Clemente, J. C., Quince, C., and Knight, R. (2011). UCHIME improves sensitivity and speed of chimera detection. Bioinformatics. 27, 2194-2200. doi: 10.1093/bioinformatics/btr381

Erickson, K. L., and Hubbard, N. E. (2000). Probiotic immunomodulation in health and disease. J. Nutr. 130, 403S-409S. doi: 10.1093/jn/130.2.403S

Estrada, A., Drew, M. D., and Van Kessel, A. (2001). Effect of the dietary supplementation of fructooligosaccharides and Bifidobacteriumlongum to early-weaned pigs on performance and fecal bacterial populations. Can. J. Anim. Sci. 81, 141-148. doi: 10.4141/A00-037

Fiocchi, A., Burks, W., Bahna, S. L., Bielory, L., Boyle, R. J., Cocco, R., et al. (2012). Clinical use of probiotics in pediatric allergy (CUPPA): a world allergy organization position paper. WAO J. 5, 148-167. doi: 10.1097/WOX. ob013e3182784ee0
31572415), National Natural Science Foundation of Jilin (Grant No. 20160101348JC), and Key Construction Program of Jilin Province (Grant No. 201802010 $18 \mathrm{NY})$.

Friesen, K. G., Goodband, R. D., Nelssen, J. L., Blecha, F., Reddy, D. N., Reddy, P. G., et al. (1993). The effect of pre- and postweaning exposure to soybean meal on growth performance and on the immune response in the early-weaned pig. J. Ani. Sci. 71, 2089-2098. doi: 10.2527/1993.7182089x

Frossard, C. P., Steidler, L., and Eigenmann, P. A. (2007). Oral administration of an IL-10-secreting Lactococcuslactis strain prevents food-induced IgE sensitization. J. Allergy Clin. Immunol. 119, 952-959. doi: 10.1016/j.jaci.2006. 12.615

Gourbeyre, P., Desbuards, N., Grémy, G., Tranquet, O., Champ, M., Denery-Papini, S., et al. (2013). Perinatal and postweaning exposure to galactooligosaccharides/inulin prebiotics induced biomarkers linked to tolerance mechanism in a mouse model of strong allergic sensitization. J. Agric. Food Chem. 61, 6311-6320. doi: 10.1021/jf305315g

Guo, P., Piao, X., Ou, D., Li, D., and Hao, Y. (2007). Characterization of the antigenic specificity of soybean protein beta-conglycinin and its effects on growth and immune function in rats. Arch. Anim. Nutr. 61, 189-200. doi: 10.1080/17450390701318358

Hao, Y., Li, D. F., Piao, X. L., and Piao, X. S. (2010). Forsythia suspensa extract alleviates hypersensitivity induced by soybean $\beta$-conglycinin in weaned piglets. J. Ethnopharmacol. 128, 412-418. doi: 10.1016/j.jep.2010.01.035

Holt, P. G., and Jones, C. A. (2000). The development of the immune system during pregnancy and early life. Allergy 55, 688-697. doi: 10.1034/j.1398-9995.2000. 00118.x

Hrncir, T., Stepankova, R., Kozakova, H., Hudcovic, T., and TlaskalovaHogenova, H. (2008). Gut microbiota and lipopolysaccharide content of the diet influence development of regulatory $\mathrm{T}$ cells: studies in germ-free mice. BMC Immunol. 9:65. doi: 10.1186/1471-2172-9-65

Huang, Q., Xu, H. B., Yu, Z., Gao, P., and Liu, S. (2010). Inbred chinesewuzhishan (WZS) minipigmodel for soybeanglycinin and $\beta$-conglycininallergy. J. Agric. Food Chem. 58, 5194-5198. doi: 10.1021/jf904536v

Julie, W., Sangita, P. P., Nan, Y., Jimmy, K., Joohee, L., Sally, N., et al. (2010). Safety, tolerability, and immunologic effects of a food allergy herbal formula in food allergic individuals: a randomized, double-blinded, placebo-controlled, dose escalation, phase 1 study. Ann. Allergy Asthma Immunol. 105, 75-84. doi: 10.1016/j.anai.2010.05.005

Langlands, S. J., Hopkins, M. J., Coleman, N., and Cummings, J. H. (2004). Prebiotic carbohydrates modify the mucosa associated micro-flora of the human large bowel. Gut 53, 1610-1616. doi: 10.1136/gut.2003.037580

Lanning, D., Sethupathi, P., Rhee, K. J., Zhai, S. K., and Knight, K. L. (2000). Intestinal microflora and diversification of the rabbit antibody repertoire. J. Immunol. 165, 2012-2019. doi: 10.4049/jimmunol.165.4.2012

Lin, H., Su, B., Chen, A., Lin, T., Tsai, C., Yeh, T., et al. (2006). Oral probiotics reduce the incidence and severity of necrotizing enterocolitis in very low birth weight infants. Pediatrics 115, 1-4. doi: 10.1542/peds.2004-1463

Liu, G., Bei, J., Liang, L., Yu, G., Li, L., and Li, Q. (2018). Stachyose improves inflammation through modulating gut microbiota of high-fat diet / streptozotocin induced type 2 diabetes in rats. Mol. Nutr. Food Res. 62:1700954. doi: $10.1002 / \mathrm{mnfr} .201700954$

Ly, N. P., Litonjua, A., Gold, D. R., and Celedón, J. C. (2011). Gut microbiota, probiotics, and vitamin D: interrelated exposures influencing allergy, asthma, and obesity? J. Allergy Clin. Immunol. 127, 1087-1094. doi: 10.1016/j.jaci.2011. 02.015

Maharshak, N., Packey, C. D., Ellermann, M., Manick, S., Siddle, J., Huh, E., et al. (2013). Altered enteric microbiota ecology in interleukin 10-deficient mice during development and progression of intestinal inflammation. Gut Microbes 4, 316-324. doi: 10.4161/gmic. 25486

Martín, R., Miquel, S., Ulmer, J., Kechaou, N., Langella, P., and BermúdezHumarán, L. G. (2013). Role of commensal and probiotic bacteria in human health: a focus on inflammatory bowel disease. Microb. Cell Fact. 12, 1-11. doi: 10.1186/1475-2859-12-71

Nakamura, S., Sarker, S. A., Oku, T., Wahed, M. A., and Wagatsuma, Y. (2010). Effect of daily intake of prebiotic (fructooligosaccharide) on weight gain and 
reduction of acute diarrhea among children in a bangladesh urban slum: a randomized double-masked placebo-controlled study. Gastroenterology 138:S51. doi: 10.1016/S0016-5085(10)60231-4

Ohta, A., Uehara, M., Sakai, K., Takasaki, M., Adlercreutz, H., Morohashi, T., et al. (2002). A combination of dietary fructooligosaccharides and isoflavone conjugates increases femoral bone mineral density and equol production in ovariectomized mice. J. Nutr. 132, 2048-2054. doi: 10.1093/jn/132.7.2048

Oli, M. W., Petschow, B. W., and Buddington, R. K. (1998). Evaluation of fructooligosaccharide supplementation of oral electrolyte solutions for treatment of diarrhea (Recovery of the Intestinal Bacteria). Dig. Dis. Sci. 43, 138-147. doi: 10.1023/A:1018892524790

Pohjavuori, E., Viljanen, M., Korpela, R., Kuitunen, M., Tiittanen, M., Vaarala, O., et al. (2004). Lactobacillus GG effect in increasing IFN-gamma productionin infants with cow's milk allergy. J. Allergy Clin. Immunol. 114, 131-136. doi: 10.1016/j.jaci.2004.03.036

Prescott, V. E., and Hogan, S. P. (2006). Genetically modified plants and food hypersensitivity diseases: usage and implication of experimental models for risk assessment. Pharmacol. Ther. 111, 374-383. doi: 10.1016/j.pharmthera.2005. 10.005

Rautava, S., Kalliomaki, M., and Isolauri, E. (2005). New therapeutic strategy for combating the increasing burden of allergic disease: probiotics-A nutrition, allergy, mucosal immunology and intestinal microbiota (NAMI) research group report. J. Allergy Clin. Immunol. 116, 31-37. doi: 10.1016/j.jaci.2005.02.010

Round, J., and Mazmanian, S. (2010). Inducible Foxp3+ regulatory T-cell development by a commensal bacterium of the intestinal microbiota. Proc. Natl. Acad. Sci. 107, 12204-12209. doi: 10.1073/pnas.0909122107

Schloss, P. D., Westcott, S. L., Ryabin, T., Hall, J. R., Hartmann, M., Hollister, E. B., et al. (2009). Introducing mothur: open-source, platform-independent, community-supported software for describing and comparing microbial communities. Appl. Environ. Microb. 75, 7537-7541. doi: 10.1128/aem.01 541-09

Shida, K., Takahashi, R., Iwadate, E., Takamizawa, K., Yasui, H., Sato, T., et al. (2002). Lactobacillus casei strain shirota suppresses serum immunoglobulin E and immunoglobulin G1 responses and systemic anaphylaxis in a food allergy model. Clin. Exp. Allergy 32, 563-570. doi: 10.1046/j.0954-7894.2002.01354.x

Shin, N. R., Whon, T. W., and Bae, J. W. (2015). Proteobacteria: microbial signature of dysbiosis in gut microbiota. Trends Biotechnol. 33, 496-503. doi: 10.1016/j. tibtech.2015.06.011

Smits, H. H., Engering, A., van der Kleij, D., de Jong, E. C., Schipper, K., and van Capel, T. M. (2005). Selective probiotic bacteria induce IL-10producing regulatory $\mathrm{T}$ cells in vitro by modulating dendritic cell function through dendritic cell-specific intercellular adhesion molecule 3-grabbing nonintegrin. J. Allergy Clin. Immunol. 115, 1260-1267. doi: 10.1016/j.jaci.2005. 03.036

Sun, P., Li, D. F., Dong, B., Qiao, S. Y., and Ma, X. (2008). Effects of soybean glycinin on performance and immune function in early weaned pigs. Arch. Anim. Nutr. 62, 313-321. doi: 10.1080/174503908020 66419

Sun, P., Li, D. F., Dong, B., Qiao, S. Y., Ma, X., and Chen, X. (2009). Vitamin C:An immunomodulator that attenuates anaphylactic reactions to soybean glycinin hypersensitivity in a swine model. Food Chem. 113, 914-918. doi: 10.1016/j. foodchem.2008.08.018

Tang, C. H., and Ma, C. Y. (2009). Effect of high pressure treatment on aggregation and structural properties ofsoy protein isolate. LWT-Food Sci. Technol. 42, 606-611. doi: 10.1016/j.lwt.2008.07.012

Valcheva, R., and Dieleman, L. A. (2016). Prebiotics: definition and protective mechanisms. Best Pract. Res. Clin. Gastroenterol. 30, 27-37. doi: 10.1016/j.bpg. 2016.02.008

Van, H. E., Ruiter, B., Faber, J., M’Rabet, L., Knol, E. F., Stahl, B., et al. (2010). A specific mixture of short-chain galacto-oligosaccharides and long-chain fructooligosaccharides induces a beneficial immunoglobulin profile in infants at high risk for allergy. Allergy 64, 484-487. doi: 10.1111/j.1398-9995.2008. 01765.x
Van de Lagemaat, J., Manuel Silván, J., Javier Moreno, F., Olano, A., and Dolores del Castillo, M. (2007). In vitro glycation and antigenicity of soy proteins. Food Res. Int. 40, 153-160. doi: 10.1016/j.foodres.2006.09.006

Van den Bogert, B., Meijerink, M., Zoetendal, E., Wells, J., and Kleerebezem, M. (2014). Immunomodulatory properties of streptococcus and veillonella isolates from the human small intestine microbiota. PLoS One 9:e114277. doi: 10.1371/ journal.pone.0114277

Von der Weid, T., Bulliard, C., and Schiffrin, E. (2001). Induction by a lactic acid bacterium of a population of CD4(1) T cells with low proliferative capacity that produce transforming growth factor beta and interleukin-10. Clin. Diagn. Lab. Immunol. 8, 695-701. doi: 10.1128/CDLI.8.4.695-701.2001

Vos, A. P., van Esch, B. C., Stahl, B., M’Rabet, L., Folkerts, G., Nijkamp, F. P., et al. (2007). Dietary supplementation with specific oligosaccharide mixtures decreases parameters of allergic asthma in mice. Int. Immunopharmacol. 7, 1582-1587. doi: 10.1016/j.intimp.2007.07.024

Wang, W., Chen, J., Zhou, H., Wang, L., Ding, S., Wang, Y. W., et al. (2017). Effects of microencapsulated Lactobacillus plantarum and fructooligosaccharide on growth performance, blood immune parameters, and intestinal morphology in weaned piglets. Food Agric. Immunol. 29, 84-94. doi: 10.1080/09540105.2017. 1360254

Wang, Y., Liu, X. T., Wang, H. L., Li, D. F., Piao, X. S., and Lu, W. Q. (2014). Optimization of processing conditions forsolid-state fermented soybean meal and its effects on growth performance and nutrient digestibility ofweanling pigs. Livest. Sci. 170, 91-99. doi: 10.1016/j.livsci.2014.07.020

Watanabe, J., Sasajima, N., Aramaki, A., and Sonoyama, K. (2008). Consumption of fructo-oligosaccharide reduces 2,4-dinitrofluorobenzeneinduced contact hypersensitivity in mice. Bri. J. Nutr. 100, 339-346. doi: 10.1017/S0007114507901221

Wei, B., Wingender, G., Fujiwara, D., Chen, D. Y., McPherson, M., Brewer, S., et al. (2010). Commensal microbiota and CD8 $+\mathrm{T}$ cells shape the formation of invariant NKT cells. J. Immunol. 184, 1218-1226. doi: 10.4049/jimmunol. 0902620

Yamada, Y., Matsumoto, K., Hashimoto, N., Saikusa, M., Homma, T., Yoshihara, S., et al. (2012). Effect of Th1/Th2 cytokine pretreatment on RSV-induced gene expression in airway epithelial cells. Int. Arch. Allergy Immunol. 154, 185-194. doi: 10.1159/000321105

Yang, A., Zuo, L., Cheng, Y., Wu, Z., Li, X., Tong, P., et al. (2018). Degradation of major allergens and allergenicity reduction of soybean meal through solidstate fermentation with microorganisms. Food Funct. 9, 1899-1909. doi: 10. 1039/c7fo01824j

Zhao, Y., Qin, G. X., Sun, Z. W., Che, D. S., Bao, N., and Zhang, X. D. (2011). Effects of soybean agglutinin on intestinal barrier permeability and tight junction protein expression in weaned piglets. Int. J. Mol. Sci. 12, 8502-8512. doi: 10. 3390/ijms12128502

Zheng, L., Li, D., Li, Z. L., Kang, L. N., Jiang, Y. Y., Liu, X. Y., et al. (2017). Effects of bacillus fermentation on the protein microstructure and anti-nutritional factors of soybean meal. Lett. Appl. Microbial. 65, 520-526. doi: 10.1111/lam. 12806

Zhong, Y., Nyman, M., and Fåk, F. (2015). Modulation of gut microbiota in rats fed high- fat diets by processing whole- grain barley to barley malt. Mol. Nutr. Food Res. 59, 2066-2076. doi: 10.1002/mnfr.201500187

Conflict of Interest Statement: The authors declare that the research was conducted in the absence of any commercial or financial relationships that could be construed as a potential conflict of interest.

Copyright (c) 2018 Chang, Zhao, Qin and Zhang. This is an open-access article distributed under the terms of the Creative Commons Attribution License (CC BY). The use, distribution or reproduction in other forums is permitted, provided the original author(s) and the copyright owner(s) are credited and that the original publication in this journal is cited, in accordance with accepted academic practice. No use, distribution or reproduction is permitted which does not comply with these terms. 